\title{
MEMÓRIA E TRANSMISSÃO DAS EXPERIÊNCIAS COMO DESAFIOS PARA OS ESTUDIOSOS DA EDUCAÇÃO
}

\author{
Lívia Diana Rocha Magalhães ${ }^{1 \cdot}$ \\ Polliana Moreno dos Santos ${ }^{2}$ \\ Daniela Moura Rocha de Souza ${ }^{3}$
}

\begin{abstract}
RESUMO:
A memória social e coletiva também necessita do processo educativo para a sua transmissão e legitimação, processo que acaba justificando a luta entre o que deve ser lembrado e/ou esquecido. É nesse sentido que consideramos imprescindível que os pesquisadores da educação realizem uma reflexão acerca da escola como lugar de transmissão de memórias, bem como sobre a necessidade de nos apropriarmos das discussões teóricas sobre esse campo. Sendo assim, este trabalho objetiva reiterar a importância dos estudos da memória para o entendimento dos processos que envolvem a transmissão de saberes, através das experiências e conteúdos compartilhados no ato educativo, além de compreender o modo pelo qual esse processo pode incorrer na continuidade ou proteção de uma dada negociação sobre os conflitos presentes na sociedade. No que diz respeito à educação e à transmissão da memória/experiência, indaga-se, por exemplo, o que a escola - e logo o seu entorno social - diante dessa situação, está mantendo sob seu controle.
\end{abstract}

Palavras-chave: Memória, Experiência, Educação.

\section{MEMORY AND TRANSMISSION OF EXPERIENCES AS CHALLENGES FOR STUDIES IN EDUCATION}

\begin{abstract}
:
The social and collective memory also requires the educational process for their transmission and legitimation, a process that ends justifying the struggle between what shold be remembered and/or forgotten. That is why we consider essential that education researchers conducting an analysis about the school as a place of transmission of memories, as well as on the need to appropriate the theoretical discussions about this field. Thus, this paper aims to reiterate the importance of studies of memory in understanding the processes that involve the transfer of knowledge through the experiences and content shared on the educational act, and understand the way in which this process may incur in the continuity or protection of a given trading on the conflicts in society. With regard to education and transmission of memory / experience, he asks, for example, that school - and soon their social environment - in this situation, is keeping under its control.
\end{abstract}

Keywords: Memory, Experience, Education.

Revista HISTEDBR On-line, Campinas, n.36, p. 105-114, dez.2009 - ISSN: 1676-2584 
O presente texto tem como objetivo apresentar um conjunto de indagações sobre o tema da memória e sua imbricação com os processos de transmissão e recepção de experiências, considerando que falar em memória e educação, implica, necessariamente em discutir as experiências coletivas, herdadas socialmente, bem como os acordos, tensões e conflitos que decorrem desse processo. Neste sentido, nos parece pertinente indagar sobre qual tem sido a nossa interpelação sobre a relação entre a educação escolar e a transmissão de experiências e da sua memória, sobre a história científica e a memória históricosocial. Se temos discutido as interpretações hegemônicas sobre a nossa história nacional, sobre a história e a memória construída sobre os diversos grupos e classes da nossa sociedade e se estamos nos acercado principalmente na sala de aula, das discussões sobre as memórias que esses grupos têm produzido para preservar e transmitir sobre o seu passado. Antes, situamos algumas referências sobre o campo de estudos da memória que consideramos importante para discutir o tema proposto.

Nos séculos XX e XXI, os estudos teóricos sobre a memória ganham visibilidade e provocam inúmeros debates a partir de muitas tendências e perspectivas teóricas, seja como uma das dimensões para o entendimento da manutenção da cultura, seja como resposta a reivindicações socioculturais, como objetivo de recuperação de experiências sociais e políticas ou como categoria histórica e historiográfica, entre outras abordagens. Conferindo, por sua vez, o caráter multimodal e multidisciplinar a essa área.

Esses estudos têm sido bastante apropriados pelas ciências sociais e humanas, e apresentado a possibilidade de desdobramentos fundamentais para a análise de uma realidade que muitas vezes está latente, submersa, pouco apreendida a partir das ciências convencionais. Na maioria das vezes, trata-se de rebrotar objetos e temas já tão tratados por várias áreas do conhecimento, mas que ainda estão requerendo outras abordagens, e que se tornam possíveis, entre outras, a partir das discussões trazidas pelas teorias da memória.

Toda memória individual é também social, uma vez que a mesma não brota de indivíduos isolados, mas sim dos marcos de necessidades e valores de uma sociedade, como afirmara Halbwachs (2006). Desse modo, o conceito de memória coletiva ganha significado, sobretudo, por meio do referido autor, a partir de sua indução teórica com base em Durkheim, ou seja, da determinação do fato social sobre os indivíduos e grupos.

Para Halbwachs (2006), a memória se relaciona de maneira sistemática com os grupos sociais, por isso propôs a noção de memória coletiva, concluindo que toda lembrança era sempre coletiva, e não havia como separar a memória individual da sua construção social. As discussões teóricas inauguradas pelo referido autor no início do século XX foram muito importantes para o campo de estudos da memória, principalmente a partir do prisma das ciências sociais, quando discute a base social da memória, que até então era considerada como um objeto particular e meramente fenomenológico, psicológico e/ou biológico. Embora não se possa deixar de registrar que o psicólogo russo Lev Vygotsky, nos anos trinta, também já havia tratado de uma teoria da mente humana que era inseparável da sua dimensão social.

Boa parte dos estudos sobre a memória passou, assim, a se debruçar sobre a questão social da memória e sua relação com o presente vivido pelos grupos sociais, como foi o caso do psicólogo social Frederic Bartlett (1932-1995), que elaborou uma teoria da memória a partir de uma perspectiva psicossocial, tornando-se, juntamente com 
Halbwachs, uma referência para o estudo do tema, afirmando que não há memórias propriamente armazenadas na mente ou cérebro, mas sim traços deixados pelas experiências (esquemas) que se transformam cada vez que são ativadas para produzir uma experiência concreta (ROSA, et al, p.45).

Para Bartlett, a memória faz parte do processo de conhecimento e reconhecimento do mundo, que é definido pela busca de sentido. Este autor defendia a ideia de que, para ser lembrado, primeiramente é preciso ter percebido aquilo que estava sendo lembrado (SÁ, 2007), ou seja, os indivíduos utilizariam o que guardaram das experiências pretéritas, quando perceberem algo novo; é o que ele chama de rememoração, em vez de percepção, como concebia Bergson (1999).

Paul Ricoeur (2007), do seu ponto de vista hermenêutico, considera que as memórias coletivas são reconstruções sociais, imersas em narrativas que servem para adaptar-se às necessidades do presente. Ou seja, de acordo com o autor, para que haja essa memória reconstruída é necessário que haja uma interpretação de seu sentido.

E, para esse texto, por ora, basta o entendimento de que toda memória é social, e a memória coletiva decorre das experiências vividas ou herdadas, recebidas por grupos sociais, se origina e é resultado de realidades construídas pela memória social. É claro, uma afirmação que ainda poderia ser questionada a partir de muitas outras perspectivas como, por exemplo, de que há muitas memórias coletivas contidas na memória social, podendo-se dizer, entre outras observações, que dependem dos marcos ideológicos, de classe, de uma sociedade, etc.

Desse modo, falar em memória, hoje, implica, portanto, necessariamente discutir a transmissão de experiências e o conjunto de complexidades que daí decorre, ou seja, como ocorre o processo de transmissão e recepção das experiências coletivas, sociais, herdadas, construídas e aceitas, mantidas em sua transformação pelas diversas gerações, etc. E aqui comparece uma questão fundamental: que experiências estão sendo transmitidas às novas gerações? Ou seja, como tem se dado o cotejamento entre as memórias experiências, nas instituições e nos múltiplos espaços sociais?

Com base em Manheim (1993), Magalhães (2007) e Aróstegui (2004) destacam que, mesmo vivendo juntos no mesmo espaço sócio-histórico os contemporâneos e os coetâneos, são os segundos que formam grupos que compartilham experiências e vivências comuns, formando as gerações. As experiências fazem parte do presente de uma geração, que compartilha comportamentos, hábitos, e vivências comuns e continuam na medida em que vão envelhecendo juntos. São grupos contemporâneos que são formados por vários grupos coetâneos, produzindo, assim, múltiplas estratificações de vivências/experiências que convivem contraditoriamente no seio de um mesmo momento histórico, uma vez que não se pode perder de vista o fato de que essas experiências são frutos de relações sincrônicas e diacrônicas. Assim sendo, pode-se afirmar que existem muitas memórias coletivas geracionais que se cruzam no presente histórico, ou seja, memórias herdadas, transmitidas, recebidas e transformadas pelos novos portadores de cultura, como diria Manheim (1993), ou melhor, dir-se-iam novos e velhos portadores de memórias coletivas e sociais, na sua dialética.

Se tomarmos, por exemplo, a realidade dentro das escolas, verificaremos que há muitos coetâneos que pertencem a determinadas coortes de idade, e formam grupos de acordo com as afinidades provenientes das vivências comuns, se relacionando com valores 
muito próximos (comportamentos, hábitos, preferências, etc.) que, por sua vez, se distinguem, mesmo com idades próximas, justamente por conta das experiências comuns compartilhadas pelos integrantes de cada grupo e pelas experiências comuns, porém diversas, que brotam das relações entre mais velhos e mais novos, trajetórias e memórias herdadas, recebidas, que se distinguem na sua unidade diversa dentro dos marcos históricos e sociais que configuram uma dada sociedade, realidade, etc.

Em síntese, como destaca Aróstegui (2004), há testemunhos vivos de uma história que permanece em aberto, quando se fala do presente. Cada grupo que integra o presente possui uma visão estratificada de vivências e de um tempo, particularizada do grupo, por estarem vivendo o mesmo período e testemunhando-o, através da coexistência, de pelo menos três grupos de idades convencionais: a criança, o adulto e o idoso, que, inclusive, podem conviver entre si dentro de um mesmo grupo, a partir das vivências comuns partilhadas que estabelecem vínculos entre grupos da mesma idade, mas também podem pertencer a um mesmo grupo de tendências, de adesão política, religiosa, educacional, etc., apesar da diferença de idade.

Tomando Manheim (1993) como referência, Aróstegui (2004) e Magalhães (1999) também consideram que os jovens podem ser formadores em potencial de "experiências novas", uma vez que sintetizam experiências e valores velhos e novos, a partir de sua relação com a memória herdada, recebida e construída conforme as necessidades mais candentes do presente em movimento. Mas isso não significa, conforme havia destacado Manheim (1993), que os jovens tendem a ser "mais revolucionários". A síntese dessas experiências e a sua reconstrução nem sempre é revolucionária, podendo, inclusive, ser reacionária, conservadora, tudo isso dependendo do lugar que se veja, e tudo depende muito do contexto histórico e das memórias coletivas que acompanham esses grupos. Em resumo, há de se perguntar que experiências estão sendo mantidas pela memória social, será que a escola e outros espaços sociais têm sido capazes de transformar a memória herdada em favor do presente, preservando ou colocando em xeque a memória de experiências do passado? Onde a memória das experiências políticas e as rebeldias coletivas estão sendo recuperadas, por exemplo, para que as novas gerações de jovens possam, como indica Falchini (2009), realizar perguntas epistemológicas e investigar a partir delas, tornar públicas as suas produções e descobrir que as políticas e as rebeldias coletivas se constituem na história do homem em comunidade?

O fato é que muito se tem falado sobre a necessidade social de recuperação da memória, considerando que o avanço da máquina, da tecnologia, ocasionou muitas interferências sobre o processo de vida, e nesse bojo a globalização, a velocidade do tempo, a perda das tradições, etc. Assim, fala-se de uma reação a esse processo de "perda" e a busca dos grupos, das comunidades, por sua memória coletiva, de traços do passado a serviço da manutenção de sua "identidade" a partir da recuperação das experiências vividas e recebidas . Inclusive gerando indagações, se pelo fato de uma sociedade integrar-se a uma conjuntura em que as mudanças estão se dando de maneira muito rápida, se o que está sendo vivido hoje é contemporâneo.

Assim, essa realidade contraditória e complexa estaria gerando memórias de experiências intensas e recentes e estariam atuando sobre as novas gerações e provocando o chamado "presentismo", ou seja, cada vez mais, as gerações mais novas desfrutam de modificações intensas na base cultural da sociedade (acesso a internet, ao mundo virtual, a 
espaços da rua, da vida pública), por exemplo, e de outras modalidades de trabalho, formando novas experiências que se distanciam cada vez mais das experiências transmitidas pelas gerações mais velhas e consubstanciando uma memória recente, memória de "flash" que se distancia da memória de experiência passadas que formaram determinados valores sociais sobre a vida, as relações sociais em seus amplos aspectos. Estaria se constituindo uma "memória fluída", fragmentada, muitas vezes colocando em xeque as instituições, como, por exemplo, a escola, sua vida de relações constituídas e fazendo contraposição a uma memória coletiva (de professores, alunos) e social sobre esses sujeitos e a escola, por exemplo, que vinham sendo mantidas por meio de suas práticas sociais, sua cultura ou culturas escolares, provocando sobre as gerações mais velhas (os professores, os pais, entre outros) e a escola, uma sensação de desmantelamento ou falta de condições de manutenção de experiências guardadas, validadas socialmente pelas memórias coletivas de seus grupos, pela história, pelos conhecimentos produzidos cientificamente, pela memória social sobre a importância da escola, etc.

$\mathrm{Na}$ verdade, uma realidade bastante multifacetada que acaba gerando a necessidade de recomposição da memória coletiva, social, sob ameaça. Falar em memória, portanto, implica necessariamente discutir a transmissão de experiências e o conjunto de complexidades que daí decorre, ou seja, que processos de transmissão e recepção das experiências coletivas, sociais, herdadas, construídas, etc., que são mantidas, valorizadas, modificadas pela prática social. Mas, como destacam Tornay e Vega (2009, p.61), "toda transmissão de saberes e sentidos do passado é uma questão aberta e pública, objeto de lutas estratégicas e políticas de memória, em que as experiências e memórias devem ser laboriosamente tratadas para que outros a recebam e a incorporem", ou seja, não há recomposição da memória sem uma dada finalidade.

No que diz respeito à educação e à transmissão da memória/experiência, indagamos, por exemplo, o que a escola e, logo, o seu entorno social, diante dessa situação social, está mantendo sob seu controle, ou seja, que políticas de memória estão sendo conservadas e como se relacionam com os grupos de alunos, de professores, enfim, de coetâneos e contemporâneos que compartilham dessa política institucional e da sociedade em curso.

Assim, vai se tornando fundamental perguntar a respeito de quais valores simbólicos, significados e intenções essas experiências estão sendo recuperadas e atualizadas, como as instituições estão tomando-as para manter as interconexões diacrônicas e sincrônicas que moldam a educação no presente.

\section{Educação, Memória e transmissão de experiências: realidade e contradições}

E aqui retornamos ao ponto de partida, a importância de analisar a memória, as experiências herdadas, mantidas ou modificadas, para se ter uma dimensão próxima da visão de mundo em que as novas gerações estão sendo educadas e até que ponto continuam-se reproduzindo relações sociais mitificadas que têm influenciado aquilo que deve ser mantido e recordado e, melhor dizendo, como os estudiosos e profissionais da área das humanas e sociais, entre eles os professores, vivem dependendo em grande medida entender essas relações. E se torna fundamental analisar que construção e difusão 
de memórias estão sendo reiteradas por meio das aulas, livros didáticos, comportamentos, imagens e outros escritos sociais.

Que memórias sociais estão atuando no presente e se evidenciado na escola? Percebemos que ainda são recentes as discussões historiográficas e a presença de políticas sociais que trazem para dentro da escola questionamentos sobre determinados discursos oficiais sob a ótica do Estado liberal, que transformaram a memória da escola em um verdadeiro mito, seja pelo discurso sobre essa instituição, seja pela constituição, determinadas narrações e explicações a partir de acontecimentos que costumam elucidar ou desenvolver certos fatos ou ditos memoráveis sobre certos grupos ou sobre seus discursos.

Nesse sentido, queremos destacar como a escola ainda se baseia em significados de um passado mitificado em torno da nossa população, principalmente de cor de pele negra, do trabalho manual, de classe social, de gênero, de religião, da própria escola, etc., que ainda precisam ser discutidos, analisados, ou melhor, reconhecidos a partir daquilo que é preciso saber sobre os processos históricos e como determinadas memórias foram negociadas ao longo do tempo e como foram se tornando componentes culturais e artificiais necessários à manutenção do status quo de nossa sociedade.

A constituição da disciplina História no Brasil é um exemplo, uma vez que participou da consolidação dos mitos fundadores da sociedade brasileira, como a "democracia das raças", a supremacia do catolicismo sobre as religiões de matriz afroameríndeas, a construção e desconstrução dos heróis nacionais, o mito de uma sociedade sem divisão de classes, capaz de produzir igualdades sociais, etc.

Mas é na realidade concreta que essas ambivalências e contradições se manifestam, também rebrotando outras memórias que dão sustentação à própria experiência vital de determinados grupos ou comunidades sociais e possibilitando a superação ou formação de outras concepções lineares sobre os mitos, a história e a cultura. E é desses processos culturais, provenientes da memória experiencial, ou seja, da que os sujeitos vivem cotidianamente, que contradizem a memória herdada, transmitida e que brotaram a reivindicação de grupos sociais, cobrando as dívidas sociais que lhes são devidas, na medida em que esse tema passa a ser discutido abertamente. De igual modo, a luta pela manutenção de determinadas experiências de reivindicações sociais que, embora não sejam como eram antes, continuam na memória coletiva e social, como é o caso das lutas sociais, dos traumas políticos, entre outras.

Contudo, uma memória coletiva, de um grupo, nem sempre alcança imediatamente a categoria de memória social, ou seja, aquela que é mais ampla, e que é reconhecida e aceita por um conjunto maior na sociedade. Como isso não se dá de uma hora para outra, está ocorrendo a exigência de que as instituições educativas e o Estado tornem mais visíveis as políticas sociais que tratem da questão dessa memória. Mas tudo indica que essas instituições estão sendo instigadas a responder por uma demanda que não esperavam. De outra parte, outras experiências, como as sindicais, entre outras, vão sendo refreadas, mantidas sob controle de várias naturezas.

Com essa última discussão, pretendemos ressaltar que os estudos da memória podem se tornar fundamentais para a análise do currículo escolar, para as discussões nos espaços acadêmicos e políticos, como uma reivindicação de revisão de experiências de grupos, de fatos e acontecimentos de práticas culturais que coloquem em evidência as 
"memórias de experiências" e os sentidos de seus usos por uma dada lógica societária. A intenção é clara: estudar a realidade à luz das teorias da memória, ampliando o leque de outras áreas que já colocaram em evidência tais fenômenos, agora tomando como tese que as experiências podem se tornar uma práxis social, por meio da memória guardada, latente, muitas vezes submersa, que precisa ser estudada, revelada, para colocar em xeque o evolucionismo decorrente de lógica de desenvolvimento de uma sociedade civilizatória que, por meio da ação progressiva e lenta do liberalismo estatal, converteu muitas memórias coletivas, principalmente de experiências políticas e da vida ordinária, em uma memória comum, que integra uma memória social de nação, de povo, de raça, etnia, gênero, de classe, etc., por meio de mediações apoiadas em soluções parciais e temporais, e em um conjunto de relações que ainda precisam ser explicadas.

$\mathrm{O}$ fato é que vivemos sob um contexto de fenômenos decorrentes do desenvolvimento técnico, que cada vez mais tem interferido de forma incidente sobre as instituições e movimentos sociais entre outros, e operacionalizado modificações profundas sobre a memória coletiva, como um valor social, sob o qual grupos instruídos e leigos, professores, pesquisadores, militantes políticos inseridos em instituições ou não, vinham defendendo e incorporando para reivindicar uma sociedade menos desigual ou excludente.

Reconstruir e ativar o passado, inclusive o ainda recente, por meio da "memória coletiva" de experiências que estão escritas ou inscritas nas relações sociais, para restituir o sentido da escola, da sociedade, o seu presente e seu futuro, significa, entre outros aspectos, instigar a escola, a academia, a revisitar as experiências registradas, seja pelo viés da relação entre história e memória, ou seja, pela sua recuperação sistematizada do ponto de vista científico de muitas fontes documentais escritas ou orais, mas também de reivindicar cotidianamente as experiências e valores, costumes que estão sendo destituídos. Por exemplo, a recuperação da memória de experiências do que foi a universidade, a escola pública no Brasil, as relações e condições de trabalho, os movimentos sociais, com o intuito de revisar as experiências por meio da reativação da memória coletiva e social, como contraposição ou denúncia do "presente" que solidifica o status quo de uma sociedade cada vez mais lucrativa, aparente, virtual, mantida sob condições tecnológicas que podem ser humanizantes, mas, em geral, favorece uma sociedade que se apropria do presente, esquecendo o passado.

Uma discussão que inclua o campo da memória como uma das análises sobre a escola e a educação supõe a discussão sobre as políticas de memória presentes na escola, na sociedade que a mantém e que reivindique a problematização da "tensão existente entre a memória como história científica" realizada por profissionais da disciplina e da memória como "memória histórico-social" que os diversos grupos ou classes da sociedade preservam e transmitem sobre o seu passado (FALCHINI, 2009, p. 35).

Como fez Pierre Nora (1993, p.11), que, ao discutir a memória pátria da França, aponta caminhos pelos quais se possam questionar memórias constituídas, no caso, pela historiografia, e que, considera-se também poder ser ampliada para amplos setores da sociedade:

[...] Reconstituir seus mitos e suas interpretações, significa que nós não nos identificamos mais completamente com a sua herança. Interrogar 
uma tradição, por mais venerável que ela seja, é não mais se reconhecer como seu único portador. Ora, não são unicamente os objetos mais sagrados de nossa tradição nacional que se propõe uma história da história; interrogando-se sobre seus meios materiais e conceituais, sobre os procedimentos de sua própria produção e as etapas sociais de sua difusão, sobre sua constituição em tradição.

Nessa perspectiva, pensar a educação supõe discutir o caráter das experiências que estão permeando o presente e aquelas que foram se acumulando ao longo do tempo e que estão inseridas na vida cotidiana das famílias, das instituições, dos alunos, professores, situados historicamente e portadores de memórias coletivas e sociais. A escola é um lugar de produção de memória, que ocorre a partir de memórias cruzadas que objetiva socializar, transmitir tanto os conhecimentos sistematizados, acumulados e selecionados, mas também experiências que contêm práticas sociais, culturais, de costumes, linguagens, historicamente validados. Mas esse processo, sabemos, não se dá sem conflitos, uma vez que os sujeitos em formação, alunos, trazem consigo a memória de experiências familiares, religiosas, de classe, enfim, outras experiências coletivas e sociais que sejam herdadas, recebidas ou vividas que adentram pela escola. Como também de outros contatos com os quais os grupos de iguais fazem parte, sua linguagem, etc.

Nessa perspectiva, falar em memória é colocar em evidência os vínculos que os sujeitos da escola mantêm com suas comunidades e grupos, classes sociais de origem, e como elas atuam sobre eles na escola, por meio de uma memória latente ou explícita, seja sobre suas compreensões sobre a comunicação que se estabelece ou não espaço da sala de aula, assim como sobre as ações de comunicação que decorrem das informações que ele recebe fora da escola, pelos meios de comunicação, entre outros.

Para esse embate, é preciso reconhecer que a escola trabalha com fragmentos dispersos, mantém sob controle a relação entre lembrança e esquecimento a depender nas necessidades do presente e do condicionamento social alcançado por uma dada sociedade.

\section{A título de conclusão:}

A educação, escolar, não escolar, se faz mediante a transmissão das experiências, e, portanto, mediante a memória. Ao mesmo tempo, a memória social, coletiva, necessita do processo educativo para a sua transmissão e legitimação, processo que justifica a luta pelo poder de se dizer o que deve ser lembrado ou esquecido. É nesse momento que concorrem a produção historiográfica, os livros didáticos, as políticas de memória, o discurso oficial com as lutas dos grupos étnicos, os militantes de setores religiosos, de organizações políticas, etc., fazendo emergir a contramemória.

Assim, reforçamos a necessidade, já apontada acima, da ampliação dos espaços onde o campo da memória seja discutido teoricamente, principalmente por educadores, pesquisadores das ciências humanas e sociais, já que o tema perpassa amplos lugares, envolve a transmissão de saberes, valores de uma sociedade, e que a escola também deve estudar as memórias, os conflitos cotidianos que envolvem a luta por uma sociedade. 


\section{REFERÊENCIAS:}

AROSTEGUI, Julio. La Historia vivida: sobre la historia del presente. Madrid: Alianza editorial, 2004.

BERGSON, Henri. Matéria e Memória: ensaio sobre a relação do corpo com o espírito. São Paulo: Martins Fortes, 1999.

FACHINI, A. In: El pasado eciente en la escuela In:Memoria e Historia del passado reciente. Problemas didáticos y disciplinares. Luciano Alonso- Adriana Falchini (editores), Universidade Nacional del Litoral, 2009.

HALBWACHS, Maurice. A memória coletiva. São Paulo: Centauro, 2006.

MAGALHÃES, Lívia Diana Rocha. A trajetória das gerações brasileiras nascidas entre 1926 e 1975: um perfil sociodemográfico. Tese (doutorado) - Universidade Estadual de Campinas. Campinas/SP: UNICAMP, 1999.

Educação, História e Memória: uma aproximação do estudo geracional. In: Revista HISTEDBR on line. Campinas: UNICAMP, 2007. $\mathrm{n}^{\circ} 28$.

MANHEIM, K. El problema de las generaciones,trad. Ignacio Sanchez de la Yncera.REIS: Revista Española de investigaciones sociológicas. Madrid, 62,p 193-224,abr/jun, 1993. Coordenação de Emilio Lamo de Espinosa.

NORA, Pierre. Entre Memória e História: a problemática dos lugares. In: Projeto História, São Paulo, 1993.

RICOEUR, Paul. A memória, a história, o esquecimento. Trad. Alain François (et al). Editora da Unicamp, Campinas: SP, 2007.

ROSA, A et al. Reepresentaciones del pasado,cultura personale idntidad nacional. In: Memória coletiva e identidade nacional. Madrid: biblioteca nova, 2000.

SÁ, Celso Pereira de. Sobre o campo de estudo da memória social: uma perspectiva psicossocial.In: Revista Psicologia Reflexão e Crítica. Rio Grande do Sul: UFRGS, 2007. V. 20. Disponível em < www.scielo.br/prc>. Acesso em julho de 2008.

TORNAY, María Laura,VEGA, Natalia. Entre la memoria y la historia: deslindes conceptuales y questiones metodológicas. In: Memoria e Historia del passado reciente. Problemas didáticos y disciplinares. Luciano Alonso- Adriana Falchini (editores), Universidade Nacional del Litoral, 2009.

VIÑAO, Antonio. Fracasam las reformas educativas? La respuesta de un Historiador".In: Educação no Brasil: história e historiografia. Campinas: Autores Associados; São Paulo: Sociedade brasileira de História da Educação- SBHE, 2001. 
${ }^{1}$ Doutora em Educação pela UNICAMP, professora Titular da UESB, Coordenadora do Museu Pedagógico e vice-coordenadora do Mestrado em Memória: Linguagem e Sociedade, lrochamagalhaes@gmail.com.

2 Aluna do Mestrado em Memória: Linguagem e Sociedade da UESB- Bolsista da Fapesb, pollisan1@yahoo.com.br.

${ }^{3}$ Mestre em Memória: Linguagem e Sociedade pela UESB, danyopera@ yahoo.com.br.

Artigo recebido em: 09/02/10

Aprovado para publicação em: 13/04/10 